\title{
Writing Errors in Changing the English Direct Simple Past Declarative Sentences into Indirect Speech Past Perfect Form: A Case Study on Management Level students in Colombo Campus of SLITHM
}

\author{
Ramanayaka S.K.L.J ${ }^{1}$ ，\& Premaratna C. D. H. M. ${ }^{2}$ \\ Department of Linguistics \\ University of Kelaniya, Sri Lanka
}

DOI: 10.29322/IJSRP.11.07.2021.p11546

http://dx.doi.org/10.29322/IJSRP.11.07.2021.p11546

\begin{abstract}
In English grammar, direct and indirect speech is needed because people can report or share their statements or thoughts to other people especially when they communicate between each other. The purpose of this research is to study the writing errors in changing direct simple past declarative sentences into indirect past perfect form and find solutions to overcome this problem. To collect the data questionnaire was given to find the reasons for the writing errors in changing the English direct simple past declarative sentences into indirect speech past perfect form. A pretest, an immediate test, a delay test was conducted. After the pretest lectures were conducted to teach how to use past perfect form in reported speech. The findings indicated that students make errors in sequencing of simple past tense into indirect speech past perfect form, errors in changing auxiliary verbs, pronouns, possessive adjectives, determiners and adverbials of time and place. The students found reported speech very difficult as it involves many elements, which caused students to feel confused and make many errors. Amalgamation of deductive and inductive methods appropriately to teach reported speech is highly recommended to give a better understanding to the students for avoiding mistakes. Finally, the results of this research reveal that the management level students have minimized their errors in changing the English direct simple past declarative sentences into indirect speech past perfect form.
\end{abstract}

Index Terms- Writing Errors, Declarative Sentences, Indirect speech, Deductive methods, Inductive methods,

\section{INTRODUCTION}

$\mathrm{E}^{\mathrm{n}}$ nglish is used as a first language, second language, or foreign language 1-1.6 billion people in the world today. Being able to speak English is not just about being able to communicate but it is used as a medium of commerce, science ,technology, diplomacy, art, and formal education not only in the monolingual English speaking countries but also in other countries around the world. English is the lingua franca of the modern age: a key to being a global citizen. Communication skills are an important prerequisite for a career in the Hospitality Industry. English language, being the language of the world is accepted as the formal

This publication is licensed under Creative Commons Attribution CC BY.

http://dx.doi.org/10.29322/IJSRP.11.07.2021.p11546 medium of communication. This fact is accepted and endorsed by the hoteliers alike. The importance of the English language is not just only entry level, but also spanning the entire career of hoteliers. The hotel industry, which is an integral part of the tourism industry, is very diverse in nature as it accommodates employees and guests, with a different language, ethnic and cultural backgrounds. As English is the language of the globalized business world, effective and excellent communication and adequate English language competency are essential for better guest experience and hence better efficiency, productivity and, in the long run, the profitability of the industry. It is highly vital in bringing to the fore the certain gaps created due to the lack of English Language pertaining to effective guest service. It has been also revealed that though students deem English communication as a very vital attribute, most are unable to constructively spend time,money and effort in improving it due to pragmatic attributes.Of the challenges that deter students from spending time and effort on improving their English, lack of time has been rated as the major deterrent. It has been also recognized that lack of monetary resources and support are equally challenging factors for hospitality students. Hence, English speaking leads to the confidence of the students in the Hospitality industry. Thus, for success in their chosen field, the issue of internalizing the English language is a definite must. Due to all the reasons mentioned above, it is a great challenge for the Sri Lanka Institute of Tourism and Hospitality Management (SLITHM), Colombo Campus of Sri Lanka regarding the acquisition of English as a second language and the improvement of its standard in those who enter the SLITHM. Undoubtedly, it is a greater challenge to those who follow the courses in the English medium. Making numerous errors of reported speech is not good as when someone reports incorrectly what someone else has said, it is difficult for listeners to comprehend or it is even easy for them to misunderstand, causing serious consequences. In addition, reported speech often appears on assessments, final tests and placement tests at Sri Lanka Institute of Tourism and Hotel Management. This is the target that is needed for all those students to finally become competent in speaking and writing, to communicate perfectly in English. This is not an easy task for them mainly in improving writing skills. This is the main difficulty that is faced by their English lectures, in improving their writing skills. It is the 
challenge of developing the writing skill in the second language learners specially those who are at tertiary level. They not only need skills in speaking but also ought to be at a level where they are able effectively to transmit their knowledge of wring in English as a second language.

Management level students at Sri Lanka Institute of Tourism and Hospitality Management (SLITHM), Colombo Campus (school) were chosen as samples for this research.The following observations and evaluations are done on the selected students in the sample. It has been observed that the students do not get perfect command or at least workable knowledge of reported speech even though they devote more than 13 years in their schooling. The students find the reported speech very difficult as it involves a lot of elements which causes students to feel confused and make many errors. It was also observed that grammar rules of RS were not followed when the students make attempts to answer. If students do not master this grammar point, they may lose marks relating to RS simply. Some students were better when compared to others. Insufficient familiarity with the complexity of English grammatical rules and their usage, lack of awareness of the exceptions to the rule, carelessness of grammar rules ,less usage, and less exposure to fluent English are the main reasons for the students to make the above mentioned errors. These errors particularly pose difficulty because there are students from a variety of different backgrounds, with different personal and professional interests, and different motivations for learning English. Moreover, they normally do not use the RS outside the classroom. Undoubtedly, they require a clear and effective context to present RS in a variety of situations, rather than in a single context.

English language is a compulsory subject for Management level students and writing skills are expected an optimal level. There are still so many students who have difficulties in transforming English direct speech into indirect speech. Most of the students find it difficult in utilizing direct and indirect speech of statements as they have to backshift the tense of the reported clause. They find it difficult to change tenses, pronouns and adverb of time from direct into indirect speech. The students encounter difficulties in using the English reported speech accurately, fluently, and appropriately in their real life situations.

\section{Research Elaboration}

English language proficiency is a prerequisite for a career in hospitality. Investing language skills in the hotel staff is essential to enhance the customer experience and increase profitability. Not only does the staff need to communicate successfully with the guests but also with other department employees. Few of the staff members might be able to speak in manageable English but those who do not have English as their first language suffer due to their inability and fail to understand simple instructions and information. Department heads of the Hospitality Industry often face problems such as: failing to communicate well with guests which may result in lack of confidence,among the staff members, failing to process written documents such as emails, reports and other col-laterals and failing to understand the instructions from the supervisor or manager.Being the department head, manager or owner of a hotel,one is often facing such challenges then and there and needed to look into them sooner. Therefore the writing skills have to be improved and systematically developed in the field of Hospitality studies. To study this 100 management level students were chosen as samples for this research. A pilot test was conducted for all the students to enable to find the possible influence of factors such as media, tuition, prior knowledge of reported speech with regard to past tense and past perfect tense, exposure to second language learning and also to see if there was a significant difference in terms of the errors committed both by students who had more exposure to English and less exposure to English. The sample drawn from this population is, 50 students selected from the pilot test conducted for all the 100 students. The 50 students who had done more mistakes in changing direct simple past declarative sentences into indirect past perfect when learning English as a second language were selected as the sample group from the pilot test. Out of 50 students, 25 students were selected as the experimental group and the other 25 students as the control group. Each group consisted of 13 male students and ,02 female students from urban areas and, 10 male students from rural areas.

\section{LITERATURE REVIEW}

The process by which a person learns a language is sometimes called acquisition instead of learning, because some linguists believe that the development of a L1 in a child is a special process (Richards, 1985, p.3). (Ellis, 1986, p. 292; Alice Omaggio, 1986, p. 29) explains that acquisition can be broadly defined as the internalization of rules and formulas which are then used to communicate in L2. They further say that it is the spontaneous process of rule internalization that results from natural language used while learning consists of the development of conscious L2 knowledge through formal study. In other words, acquisition is unconscious study of a language in natural way and does not depend on the language teaching. On the other hand, learning is a conscious study through formal instruction such as language classroom learning.

In Longman Dictionary of Applied Linguistics (AL), Jack Richards, et al. (1985, p. 252) states that L2 acquisition is, "the process by which people develop proficiency in a 2 or FL." Rod Ellis (1986, p. 4) explains that second language acquisition (SLA) is "a complex process, involving many interrelated factors. It is the product of many factors pertaining to the learner on the one hand and the learning situation on the other." In addition, Victoria Fromkin et. al (2002, p. 593) says that SLA is "the acquisition of another language or language after L1 acquisition that is under way or completed." To conclude, SLA is subconscious study through which a person acquires L2 or additional languages.

Like any other human learning, language learning is closely associated with the making of errors. Therefore, it is quite natural and inevitable that most, if not all language learners commit errors when they put the language to use. In this sense, errors can be seen as an integral part of language learning that are not avoidable. According to Dulay (1982), "Errors are the flawed side of learner speech or writing. They are those parts of conversation or composition that deviate from some selected norm of mature language performance. Meanwhile, Jeremy Harmer, "Errors are part of the students, inter- lingual that is the version of the language which a learner has at anyone stage of development, and 
which is continually reshaped as he or she aims toward full mastery." Thus it is apparent that Dulay's conclusion is consistent with Jeremy Harmer's conclusion.

According to Jayasundara \& Premarathna.(2011) A Linguistic Analysis on Errors Committed in English by Undergraduates of Uve Wellassa University of Sri Lanka, the students committing errors in grammar and syntax are as dependent variables. Hence, the study has explored grammar as the greatest category where undergraduates commit errors in both writing and speaking.

According to Eckhardt (2001).Reported speech: Empirical corpus findings compared with EFLIESL text book Presentations (Master's thesis, Iowa State University Capstones) the verb tense "back shifting" process advocated in the text books occurs in only 50 to 70 percent of reported speech instances. Therefore, the alternative verb tense combinations, past-present, present-present, and present-past occur more frequently than the text books claim. Findings from this study can be used to further inform their grammatical descriptions of reported speech. English as a Second/Foreign Language text book and material writers can use these findings to prioritize their presentations of reported speech according to naturally-occurring usage patterns.Mohamed,H.( 2016).A Contrastive Error Analysis,Ahmed B.A,aims at investigating the main causes behind the grammatical errors of the Algerian students at university tend to make in their written production. Based on the contrastive error analysis procedure, the focus is made on the contrast and comparison of the two basic morphosyntactic systems of English and Arabic to predict and explain the unnatural word combination as well as the morphological errors.

Yao,B.(2011).Mental Simulations in Comprehension of Direct versus Indirect Speech Quotations proves that individuals are more likely to mentally simulate or imagine reported speakers' voices and perhaps also their facial expressions during comprehension of direct as opposed to indirect speech, indicating a more vivid representation of former. The findings are in line with the demonstration hypothesis of direct speech and embodied theories of language comprehension, suggesting that sensory experiences with pragmatically distinct reporting styles underlie language comprehension.

In order to analyze learner language in an appropriate perspective, it is important to make a distinction between errors and mistakes. A mistake refers to a performance error that is either a random guess or a "slip", in that it is a failure to utilize a known system correctly. James. (1990) distinguished between error and mistake. He defined errors as systematic mistakes due to lack of language competence, while mistakes refer to performance errors because of a random guess or slip. Errors cannot be self-corrected. Mistake can be self-corrected if the deviation is pointed out to the speaker.

Meanwhile, Edge (1989) gave a simple definition. He stated that a slip or mistake is what a learner can self-correct and error is what a learner cannot self correct.

Base on the statement above, it can be elaborated that errors and mistakes are different. Error is flawed side of learner speech caused by the factor competence. It cannot be self-corrected. Besides mistakes refer to performance errors because of a random guess or slip. It can be self-corrected.
Brown stated that, "An error is a noticeable deviation from the adult grammar of a native speaker, reflecting the interlinguall competence of the learner." From all definition above, it can be comprehended that an error is a flawed side of learner speech caused by the factor of competence. On the other hand, they do not understand well the use of linguistics system of TL, it will lead the students to make errors.

Errors play an important role in English learning process because committing and analyzing errors will help learners realize and try to avoid them better. According to Corder (1974), an error is referred to as a linguistic form that is either superficially deviant or inappropriate in terms of the TL.

According to "Longman Dictionary of Language Teaching and Applied Linguistics" by Richard et al, error is considered as "the uses of a linguistic item (e.g. a word, a grammatical item, a speech act, etc.) in a way in which a fluent or native speaker of language regards as showing faulty or incomplete learning".A lot of definitions of errors have been given due to various standards. From those, the writer may suggest another definition "errors are what the L2 learners' produce, which are unacceptable, unnatural and faulty to native speaker in the particular context."

The procedure explained by Corder (1974) had been utilized to conduct error analysis

And identified errors through written tests and questionnaires. The errors were classified into 07 main categories as errors related to tense sequence, verb change, pronoun change,adverb change, common auxiliary change,modal auxiliary changeand determiner change.However,the foremost aim of conducting this research is to educate the reader about the writing errors committed by English medium

\section{METHODOLOGY}

Writing is the most difficult task in mastering the four language skills faced by second language learners. In order to collect the data of this teaching programme, the questionnaire was given. The aim of this questionnaire was to find out the reasons for the writing errors in Indirect speech past perfect form. A pretest was conducted on changing the English direct simple past declarative into indirect speech past perfect form to grasp the students writing skills. After the pretest lectures were conducted to teach how to use past

Finally, perfect form in reported speech. In addition, written corrective feedback methods were utilized to evaluate the effect of lecturing; direct written corrective feedback, indirect written corrective feedback, and metalinguistic written corrective feedback and focused written corrective feedback. After utilizing the most appropriate feedback methods, an immediate test was given to measure their progress. a delay test was led to check the progress of their writing skills. Eclectic approach which was utilized in this study is a method of language learning/teaching that combines various approaches and methodologies to teach language depending on the aims of the lesson and the abilities of the learners. This approach had more flexibility and adaptability to choose best elements according to the need and aim of the students. Different teaching methods were utilized and adapted to 
suit the requirement of the learners. It broke the monotony of the class.

Simple eclecticism which involved the integration of the below mentioned two methods in one lesson was deployed to make the lectures effective. Deductive and communicative language teaching approaches were utilized during the treatment for the management level students in the experimental group to teach reported speech.

Deductive teaching is a traditional method in which information about the TL and rules is given at the beginning of a class and complemented with examples. The principles of this approach are generally used in classes where the main target is to teach grammar structures. It gets straight forward to the point; therefore, it is time-saving. It increases students' confidence in examinations written with accuracy as the main criterion of success. It allows the teacher to deal with language points as they come up rather than having to anticipate them and prepare them in advance. deductive method to a grammar teaching underlines explaining the grammar item to learners and then training them in applying it, deductive way is said to be more teacher-centered. The deductive method is easier to apply leaving little space for mistakes, provided it is explained in a correct and precise way. The deductive approach encourages students' confidence through numerous examples, at the same time stating clearly what students are expected to learn. The following 03 steps were used by the lecturer to explain how to change direct simple past declarative sentences into indirect past perfect.

\section{(a) First Step}

The lecturer provided clear definitions and explanations of the changes of the tense sequence, verb change, pronoun change, adverb change, common auxiliary change, modal auxiliary change and determiner change from simple past tense to past perfect tense in reported speech to the management level students. The lecturer provided students with comprehensible explanation which could be easily applied to the exercises that follow.
Then the lecturer provided examples of direct simple past declarative sentences where each of the above stated grammar points were usually used,provided the answers with explanations and got the management level students to copy them accurately in their writing books. The lecture gave sufficient time for the students to ask clarifying questions to ensure understanding and cleared all the student's doubts.

\section{(c) Third Step}

The students were given direct simple past declarative sentences to change into indirect past perfect with all the grammar points discussed earlier.Then after a sufficient time all the answers were discussed eliciting answers from the students. Then management level students practised the rule providing their own examples at the end of a lesson.

Communicative language teaching approach enhanced learning autonomy and self-reliance, the management level students were more actively involved in the learning process. It favoured pattern-recognition and problem-solving abilities because grammar was taught in context. The below stated approaches were utilized by the lecturer in teaching how to change direct simple past declarative sentences into indirect past perfect.

\section{DATA ANALYSIS \& FINDINGS}

Following the guide lines presented by Corder in 1974 ( collecting samples of learner language, identifying the errors,describing the errors,explaining the errors and evaluating /correcting the errors) to analyze the errors in written tests and tasks were collected from the 50 management level students at SLITHM.

\section{A. Errors Committed in the Pretest}

The types and the percentages of errors found in the pretest are displayed in the figure $01-1$ below.It is very obvious that the percentages of errors done by both the experimental group and the control group are almost the same.

(b) Second Step

\section{Figure 01-1 Categorical distribution of errors committed in pretest}

\begin{tabular}{|l|c|c|c|c|c|c|c|c|}
\hline \multirow{2}{*}{ Type of Test } & \multicolumn{6}{c|}{ Type of Error and Their Percentages } \\
\cline { 3 - 8 } & & Tense & Verb & Pronoun & Adverb & Common & Modal & Determiner \\
\cline { 3 - 9 } & Sequence & Change & Change & Change & Auxiliary & Auxiliary & Change \\
\hline Pretest & $\begin{array}{c}\text { Experimental } \\
\text { Group }\end{array}$ & $24 \%$ & $19 \%$ & $14 \%$ & $13 \%$ & $11 \%$ & $10 \%$ & $09 \%$ \\
\cline { 2 - 9 } & Control Group & $24 \%$ & $15 \%$ & $14 \%$ & $11 \%$ & $10 \%$ & $07 \%$ & $05 \%$ \\
\hline
\end{tabular}

According to the above figure $01-1$, it is evident that the highest and the second highest percentage of errors done by both the experimental group and the control group are the tense sequence and verb change respectively. Further, lowest percentage of errors done by both the experimental group and the control group is determiner change. Furthermore, the percentages of 
errors of the pronoun change and adverb change in both the experimental group and the control group are almost the same. Moreover, it is a significant fact that the percentages of errors of the common auxiliary change and the modal auxiliary change are also more or less the same.
B. Errors Committed during the Treatment

The below figure 01-2 precisely portrays the difference between the error percentages of both the experimental group and the control group during task 1 and task 2 .

Figure 01-2 Categorical distribution of errors committed in tasks during the treatment

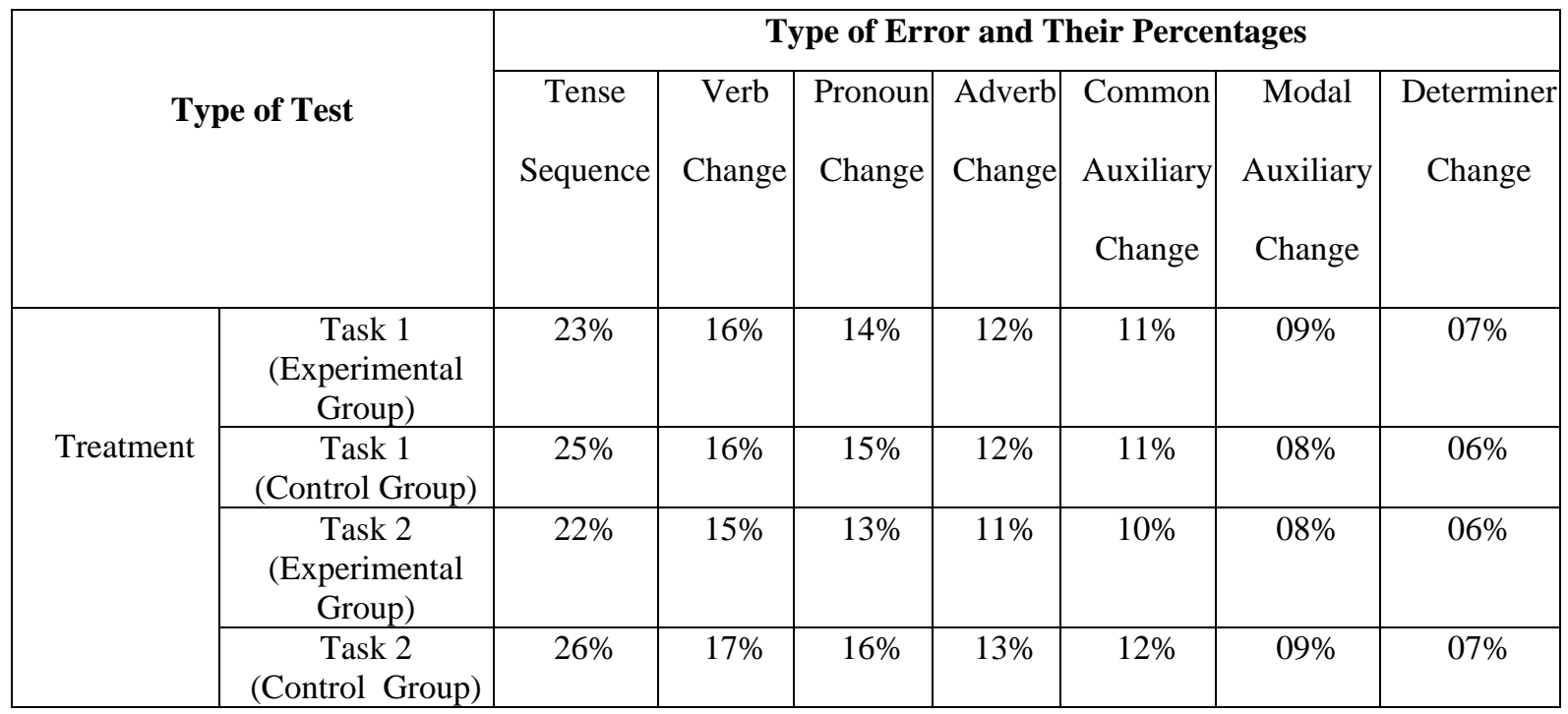

According to the figure $01-2$, it is obvious that there is a slight reduction of the percentages of all errors in the experimental group and there is a slight increase of the percentages of all errors in the control group. It is significant to notify that the highest and the lowest percentages of errors in both the experimental group and the control group remain the same as in the pretest. Further, the descending order of the percentages of all types of errors remain the same as in the pretest.

\section{Errors Committed in the Immediate test}

The below figure 01-3 illustrates that the percentages of all types of errors committed by the experimental group further had got decreased and the experimental group while the percentages of all types of errors committed by the control group had further got increased.

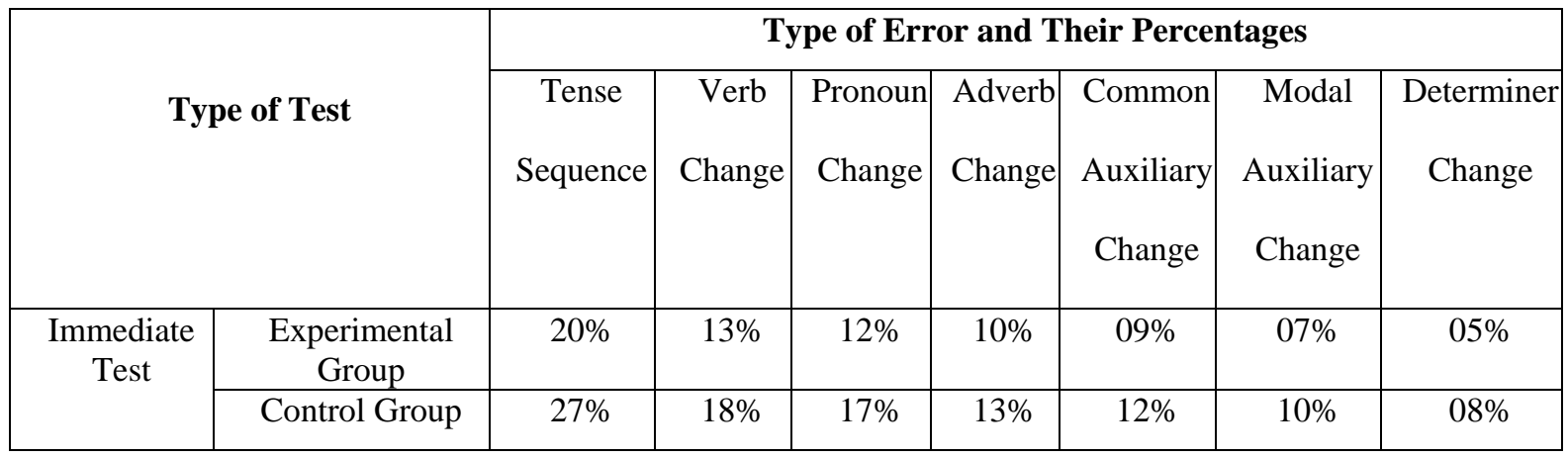

Figure 01-3 Categorical distribution of errors committed in the immediate test

According to the above figure 01-3, it is worth noting that there is a considerable amount of difference between the percentages of all errors in the experimental and the control group. When the percentage of errors of tense sequence is considered,the highest difference of $7 \%$ can be spotted. Further there is a $5 \%$ difference of errors committed in the verb change and pronoun change between the experimental and control groups which is also a considerable amount to contemplate. When the difference of percentages of adverb change ,common auxiliary change, modal auxiliary change and determiner change between the experimental and the control group are considered, it can be scrutinized as minimal. 


\section{Errors Committed in the Post Test}

Figure 01-4 stated below clearly elaborates the difference of the error percentages between the experimental and the control group extensively. It is observed that the difference between each type of error percentages in the experimental and the control group has been increased furthermore.

Figure 01-4 Categorical distribution of errors committed in written tests and tasks

\begin{tabular}{|c|c|c|c|c|c|c|c|c|}
\hline \multirow{2}{*}{\multicolumn{2}{|c|}{ Type of Test }} & \multicolumn{6}{|c|}{ Type of Error and Their Percentages } \\
\cline { 2 - 9 } & Tense & Verb & Pronoun & Adverb & Common & Modal & Determiner \\
Sequence & Change & Change & Change & Auxiliary & Auxiliary & Change \\
Change & Change & \\
\hline Post Test & $\begin{array}{c}\text { Experimental } \\
\text { Group }\end{array}$ & $19 \%$ & $12 \%$ & $11 \%$ & $09 \%$ & $08 \%$ & $06 \%$ & $04 \%$ \\
\cline { 2 - 9 } & Control Group & $28 \%$ & $19 \%$ & $18 \%$ & $14 \%$ & $12 \%$ & $11 \%$ & $09 \%$ \\
\hline
\end{tabular}

According to the figure 01-4, the highest difference between the experimental and the control group in terms of all the types of errors can be seen which is a remarkable factor. Among all the differences, $9 \%$ in the tense sequence is the highest. $7 \%$ difference in the verb change and the pronoun change is also a higher amount when compared with the highest percentage. Further it is important to state that $5 \%$ difference in the adverb change, $6 \%$ difference in the common auxiliary change,5\% difference in the modal auxiliary change and 5\% difference in the determiner change are also significant. This is a great evidence to prove that there had been a significant impact of the innovative teaching approaches on the management level students in the experimental group.

Errors found in written tests and tasks were ranked after analysing them; the dominant errors error which has indicated almost $20 \%$ of total number of errors was reported under tense sequence and the least common error which has indicated almost $5 \%$ of errors was reported under determiner change. According to the above figure 01-1, figure 01-2, figure 01-3 and figure 01-4 it is obvious that the second highest percentage of errors was reported under verb change. Subsequently, almost same percentages of errors were reported under pronoun Change and adverb change. Moreover, the almost same percentages of errors were reported under common auxiliary change and modal auxiliary change. When the percentages of all types of errors are placed in descending order stated below, it obvious that they are same in all the tests and tasks.
i. Tense Sequence
ii. Verb Change
iii. Pronoun Change
iv. Adverb Change
v. Common Auxiliary Change
vi. Modal Auxiliary Change
vii. Determiner Change

significant that all most all the management level students in the control group had used the complementizer 'that' appropriately in RS. Moreover spelling and punctuation errors

were continued to be less. Therefore they were not considered as major errors.

\section{DISCUSSION}

In the academic environment, it is noteworthy of using the correct reported speech to produce a good piece of writing, give correct directives, respond to clients in the hospitality industry as well as be fluent in the language. Further, fluency in English directly adds value to the students' career and in the Sri Lankan context. It is one of the ways to strengthen. Richards, (1972:83) also identified 'English' as a key to social mobility. In addition, exposure to English plays a major role in scoring marks in examinations, oral presentations, etc. When concluding the result as the errors that management level students committed were basically grammatical rules in reported speech. Further, emphasis indicated that the problems of the management level students had in acquiring normal reported speech rules. The tense sequence had been a challenging aspect for management level students who learn English as an L2 because their L1 syntax is not the same as that of L2. The tense sequence might have been challenging to the management level students as the tense sequence features of their L2 and L1 are often different. Therefore it seems that most management level students had experienced difficulties with regard to tense sequencing in reported speech due to mother tongue influence which can be highlighted as the common challenge. It had been evident that some management level students had used helping verb in the past tense instead of the common auxiliary verb 'had' together with the past tense form of the main verb in reported speech due to the over-generalization of the rule and insufficient knowledge of reported speech. The lack of a tense system in the students' languages made it difficult for them to use tenses correctly and organize all the parts of the different parts of the sentence correctly. The significance of teaching and learning reported speech in the field of the hospitality sector is highlighted through all the findings discussed above and further, it is important to search the reasons for these errors in 
order to enhance the performances of management level students in their hospitality career. Correct usage of tenses is an indication of speaking accurately in English, lack of exposure to correct English, lack of resources, insufficient instructions on reported speech rules have made it difficult for most of the management level students to utilize reported speech correctly. Furthermore, some of the management level students had not taken into cognizance the change of common auxiliary verbs in reported speech and that demonstrates learning or memorization of grammar aspects without proper application. Moreover, the management level students must have done many more errors due to tense sequencing, because the tense change from past tense to past perfect in changing direct simple past declarative sentences into indirect past perfect would have complicated for them. The management level students' inability was caused by the overgeneralization of the reported speech rules applied in past tense declarative sentences. They had changed the main verb unnecessarily instead of the modal auxiliary. Hence, the students' over-generalization of grammar rules caused errors extensively. The findings also reveal that the students' memorization of grammar rules does not always yield good results. Again, the sophisticated process of applying previously learned or existing knowledge might have caused the error as a result. The tense sequence had been a challenging aspect for management-level students who learn English as a second language. The tense sequence might have been challenging to the management level students as they had confused the back shift of tense in reported speech. Therefore, it seems that most management level students had had trouble with regard to tense sequencing in reported speech. In addition, this finding is stages in-congruent with the suggestion that pronouns are supposed to be mastered at early of life and or learning for L2 learners. Therefore, the management level students had already mastered the first and possessive pronouns as they did not experience any difficulties. The challenge might have been the lack of frequent usage of the time and place expressions. The insinuation might be the participants lived in environments that provided little opportunity for the natural uninstructed acquisition of all the English language. The qualitative data obtained from the pilot test support this view.

Management level students in changing the English direct simple past declarative sentences into indirect speech past perfect form discovering the most frequent errors in their writing . Consequently, findings of the research tend to suggest remedial activities giving the advancement to future management level students who will use English as the medium of instructions.

\section{CONCLUSION}

It can be concluded that most errors had been caused by the lack of competence of the English language being learned. Therefore the management level students had produced incomplete rule application, faulty generalization and failure to learn conditions under which reported speech rules to apply. With regard to error causes, it has been found the incomplete application of rules, wrong analysis and wrong use of collocation patterns are the main sources.

Writing is an important creative method within the language communication system Whether in one`s first language or a second language. The language instructors need to give proper guidance and support to get and develop it. It will help students to express their writing skills in words and express themselves using the proper grammatical rules. So that the correct message can be transferred. The results of this study convey some important aspects of innovative approaches and technologies for teaching indirect speech. To develop language skills especially writing, one needs to be given the right guidance and good resources to support. Multiple teaching methods and practical writing proved many benefits to students.

Consequently, to reduce the grammatical errors of the second language learners, components should be taught in a practical application. Moreover, the Collective feedback correction method should be used to helped second language learners recognize and understand their mistakes while correcting them themselves. Therefore, these types of methods help learners understand the difficulties they face in their writing.

\section{REFERENCES}

[1] [1] Corder, S.P. (1967) The significance of learners' errors. Errors Analysis London: Longman Group

[2] [2] Dulay, H., Burt, M \& Krashen, S. (1982) Language Two. Oxford: Oxford

[3] University Press

[4] [3] Abdullah, A. T. H. (2013). Error analysis on the use of the simple present tense and the simple past tense in writing essays among TESL college students. International Journal of Education and Researc

[5] [ 4] Richards, J.C. 1974. Error Analysis Perspective on Second Language Acquisition. London:Cambridge University Press.

[6] [5 ] Nzama, M. V. 2004. Error Analysis: A Study of Errors Commited by Isizulu Speaking Learners of English in Selected School. University of Zululand (Online),

[7] [6 ] Ahour, T. \& Mukandan, J. (2012). Error and variations of TESL students' written description. Pertanika Journal Social Science and Humanities

[8] [ 7] Jayasundara J.M.P.V.K., Premarathna C.D.H.M.(2011) A Linguistic Analysis on Errors Committed in English by Undergraduates of Uva Wellassa University of Sri Lanka publication at: International Journal of Scientific and Research Publications

[9] [9] Andersson, L. (2008). Errors made in time and tense: An investigation of errors made in time and tense in composition writing by 9 th grade learners of English in Sweden: Gotebrag University, Department of English, and Linguistic C-essay. Interdisciplinary paper.

[10] [10 ] Bhela, B. (1999). Native language interference in learning a second language: Exploratory case studies of native language interference with target language usage. International Education Journal.

[11] [11]Dennis L. Godfrey, "A Discourse Analysis of Tense in Adult ESL Monologues," in Discourse Analysis in Second Language Research, ed. Diane Larsen-Freeman Rowley, Mass.: Newbury House Publishers, 1980)

[12] [12 ] Godfrey, Dennis L. "A Discourse Analysis of Tense in Adult ESL Monologues." In Discourse Analysis in Second Language Research. Ed. Diane Larsen-Freeman. Rowley, Mass.: Newbury House Publishers, 1980.

[13] [13] Robinett, Betty Wallace and Jacquelyn Schachter, ed. Second Language Learning: Contrastive Analysis, Error Analysis and Related Aspects. Ann Arbor: The University of Michigan Press, 1983.

[14] [14] Brumfit C.J and Johnson K (ed.), "The Communicative Approach to Language Teaching", (ELBS/Oxford university press), UK, 1979.

[15] [15 ] Corder, S. (1981) Error Analysis and Interlanguage. London: Oxford University Press.

[16] [16 ] Richards, J.C. 1985. The Context of Language Teaching. America: Cambridge University Press.

[17] [17] Thompson, A.J and Martinet, A. V. 1986. A Practical English Grammar. New York: Oxford University Press. 


\section{AUTHORS}

First Author - Ramanayaka S.K.L.J., Qualifications: BA in English Language ( University of Sri Jayewardenepura- Sri Lanka), M.A. in Linguistics (Kelaniya university- Sri Lanka), Associated Institute: Assistant Lecturer (English) ,Lecturer-in Charge of the Language Unit at Sri Lanka Institute of Tourism and Hospitality Management, Sri Lanka,
Email address:-lathisha.rama@gmail.com

Second Author - Dr. C.D.H.M. Premaratna, Qualifications: PhD (Hitotsubashi -Japan), M.A. (Hitotsubashi- Japan), B.A.

(Kelaniya University - Sri Lanka), Associated Institute: Senior Lecturer at University of Kelaniya Sri Lanka., Email address: dissanayake@kln.ac.lk. 